\title{
Karakteristik Atom Mineral pada Osteoporosis dengan Arsitektur Porosis dan Nonporosis
}

\author{
Zairin Noor, ${ }^{1}$ Sutiman B. Sumitro, ${ }^{2}$ Mohammad Hidayat, ${ }^{3}$ Agus Hadian Rahim ${ }^{4}$ \\ ${ }^{1}$ Departemen Bedah Orthopaedi RSU Ulin-Fakultas Kedokteran Universitas Lambung Mangkurat \\ Banjarmasin, ${ }^{2}$ Departemen Biologi-Fakultas Matematika dan Ilmu Pengetahuan Alam Universitas \\ Brawijaya Malang ${ }^{3}$ Departemen Bedah Orthopaedi RSUD Saiful Anwar-Fakultas Kedokteran \\ Universitas Brawijaya Malang, ${ }^{4}$ Departemen Bedah Orthopaedi RS Dr. Hasan Sadikin-Fakultas \\ Kedokteran Universitas Padjadjaran
}

\begin{abstract}
Abstrak
Terdapat hasil yang bervariasi dalam peningkatan bone mineral density (BMD) akibat asupan kalsium mengindikasikan keterlibatan atom mineral lain dalam perkembangan struktur tulang. Kuantitas atom mineral tulang yaitu kadar atom mineral dalam struktur tulang. Penelitian ini bertujuan untuk membandingkan karakteristik atom mineral pada gambaran arsitektur (scanning electron microscope/SEM) porosis dibandingkan dengan nonporosis. Sepuluh penderita osteoporosis dengan gambaran SEM porosis dan tujuh penderita gambaran SEM nonporosis terlibat dalam penelitian ini. Tulang yang diambil ketika operasi fraktur dianalisis mikrostruktur dengan SEM dan karakter atom mineral tulang dengan X-ray fluorescence (XRF). Pemeriksaan SEM dan XRF dilaksanakan di Laboratorium Fisika Universitas Negeri Malang. Penelitian dilakukan mulai Agustus 2010 sampai Januari 2011. Uji t dilakukan untuk menentukan perbedaan kadar mineral tulang. Hasil SEM menunjukkan perbedaan porositas dan integritas trabekular antara SEM porosis dan SEM nonporosis. Analisis XRF didapatkan komposisi atom yang lebih tinggi pada tulang SEM nonporosis yaitu $\mathrm{P}, \mathrm{S}, \mathrm{Fe}, \mathrm{Ni}$, $\mathrm{Cr}, \mathrm{Pb}$, dan Si. Sebaliknya, komposisi atom yang lebih tinggi pada tulang SEM porosis adalah $\mathrm{Cu}, \mathrm{Zn}, \mathrm{Ca}, \mathrm{dan}$ Mo. Perbedaan komposisi atom tersebut tidak berbeda secara bermakna $(\mathrm{p}>0,05)$. Simpulan, perkembangan porositas pada osteoporosis tidak didasari oleh kuantitas atom mineral tulang. [MKB. 2013;45(1):23-7]
\end{abstract}

Kata kunci: Arsitektur, atom mineral, komposit, osteoporosis

\section{Mineral Atomic Characteristic on Porotic and Non Porotic Architecture of Osteoporosis}

\begin{abstract}
There was variance result in increased bone mineral density (BMD) due to calcium intake which indicates involvement of another mineral atomic in bone structure development. Bone mineral atomic quantity is the level or concentration of mineral atomic in bone structure. Aim of this study was to compare mineral atomic characteristic in architecture (scanning electron microscope/SEM) porotic and non porotic figure. Ten osteoporosis patients with porotic SEM and seven non porotic SEM patients were involved in this study. Bone which was obtained from fracture surgery was analyzed for microstructure by SEM and for bone atomic mineral characteristic by X-ray fluorescence (XRF). Analysis of SEM and XRF were done in Physics Laboratory State University of Malang. This study was done from August 2010 to January 2011. t-test was done to analyse the difference of atomic mineral level. Scanning electron microscope result showed the difference in porosity and trabecular integrity between porotic and non porotic SEM. Analysis of XRF showed atomic composition was higher in porotic SEM such as $\mathrm{P}, \mathrm{S}, \mathrm{Fe}, \mathrm{Ni}, \mathrm{Cr}, \mathrm{Pb}$ and $\mathrm{Si}$. Conversely atomic composition such as $\mathrm{Cu}, \mathrm{Zn}, \mathrm{Ca}$, and $\mathrm{Mo}$, was higher in non porotic SEM. There was no significant difference between each groups $(\mathrm{p}>0.05)$. In conclusion, the development of porocity in osteoporosis is not depend on bone mineral atomic quantity. [MKB. 2013;45(1):23-7]
\end{abstract}

Key words: Architecture, composite, mineral atomic, osteoporosis

Korespondensi: Dr. Zairin Noor, dr., SpOT(K), FICS, Departemen Bedah Orthopaedi RSU Ulin Banjarmasin jalan A. Yani Km 2 No.43 Banjarmasin 70233, mobile 0811511130, email noorzairin@gmail.com 


\section{Pendahuluan}

Osteoporosis dikarakterisasi dengan nilai bone mineral density (BMD) rendah dan degenerasi mikroarsitektur sehingga meningkatkan fragilitas dan risiko fraktur. Secara klinis, osteoporosis ditegakkan berdasarkan kejadian fraktur akibat trauma minimal pada vertebra, pinggul, proksimal humerus, serta femur. ${ }^{1-3}$ Peningkatan ekonomi dan populasi lanjut usia akan meningkatkan frekuensi osteoporosis sehingga menjadi satu permasalahan kesehatan yang perlu diperhatikan. ${ }^{4}$

Prevalensi osteoporosis di negara berkembang atau sedang berkembang tidak jelas terungkap karena sedikit penelitian. ${ }^{5}$ Pada populasi usia $>50$ tahun di negara Asia didapatkan osteoporosis lumbar spine wanita sebesar $11-46,7 \%$, dan pria $5,4-37,4 \%{ }^{6-8}$ osteoporosis leher femoral wanita sebesar $2 \%^{7}$ serta pria sebesar $6,3-11,4 \%,{ }^{7,8}$; serta osteoporosis pinggul wanita sebesar $16 \%{ }^{7}$ dan pada pria sebesar 3,8-24,3\%. ${ }^{6}$ Data "White Paper" yang telah dikeluarkan oleh Perhimpunan Osteoporosis Indonesia (PEROSI), prevalensi osteoporosis tahun 2007 mencapai $28,8 \%$ untuk pria dan $32,3 \%$ untuk wanita. ${ }^{10}$ Di Banjarmasin didapatkan prevalensi osteoporosis per tahun $24,52 \square-39,28 \%$ untukwanitadan $1 \square-3,05 \%$ untuk pria.

Paradigma yang diyakini dalam meningkatkan BMD berupa asupan kalsium yang mencukupi meskipun fakta penelitian menunjukkan hasil yang bervariasi. Insidensi fraktur panggul paling tinggi ditemukan di Amerika Utara dan Inggris meskipun asupan kalsium tinggi pada populasi tersebut. Hal yang sebaliknya, di negara dengan asupan kalsium rendah, insidensi fraktur panggul juga rendah, yakni di Afrika dan Amerika Latin. ${ }^{11}$ Hal tersebut memberikan pandangan lain bahwa konsumsi kalsium cukup tinggi tetap mempunyai risiko patah tulang yang tinggi. Dengan demikian terdapat pandangan bahwa kalsium bukan satusatunya atom yang menentukan kualitas tulang. ${ }^{12}$

Mineralisasi tulang sangat dipengaruhi oleh sifat atom yang mampu mengadakan substitusi untuk membentuk sebuah komposit. Beberapa penelitian telah berhasil mengungkap komposisi atom pada tulang normal. Penelitian BrodziakDopierala dkk. ${ }^{13}$ melihat komposisi Nickel (Ni), Mangan (Mn), Chromim (Cr), Calsium (Ca), Plumbum $(\mathrm{Pb})$, Copper $(\mathrm{Cu})$, Besi (Fe), Zinc ( $\mathrm{Zn})$, Magnesium (Mg), Kalium (K), Natrium ( $\mathrm{Na}$ ), dan Cadmium (Cd) pada berbagai irisan kepala femur yang memperlihatkan bahwa kandungan berbagai mineral pada berbagai irisan mampu menentukan fungsi stres mekanik. Penelitian oleh Zaichik dan Tzaphlidou ${ }^{14}$ dinyatakan bahwa rasio $\mathrm{Ca} / \mathrm{P}$ (Phosphor) merupakan prediktor yang lebih baik dibandingkan dengan konsentrasi $\mathrm{Ca}$ dan $\mathrm{P}$ secara tunggal untuk menilai kelainan tulang. Selain itu, juga telah dilakukan analisis atom pada osteoporosis meskipun sangat jarang. Osada dkk..$^{15}$ telah menyimpulkan bahwa paparan dosis rendah Cadmium akan meningkatkan risiko osteoporosis.

Masing-masing atom mineral memiliki sifat spesifik pada tulang. ${ }^{16}$ Kuantitas atom mineral adalah kadar atom mineral dalam struktur tulang. Kualitas atom mineral merupakan susunan atau distribusi atom mineral tulang yang membentuk struktur tulang. Pada kasus osteoporosis diagnosis dapat ditegakkan dengan pemeriksaan BMD tanpa memperhatikan arsitektur tulang bersangkutan, terlebih dengan mengkaji komposisi atom yang menyusunnya. Dengan demikian, penelitian yang melihat arsitektur tulang penderita osteoporosis dan menghubungkannya dengan komposisi atom untuk menjawab peranan kalsium dan munculnya porositas mampu memberikan pandangan baru dalam penanganan osteoporosis.

\section{Metode}

Penelitian ini merupakan penelitian deskriptif yang bersifat potong lintang. Subjek penelitian yaitu penderita yang mendapat tindakan operasi di Bagian Ortopedi RSUD Ulin Banjarmasin dan senter lain dengan kriteria inklusi tulang trabekular yang mendapat fraktur (penderita yang dioperasi), BMD osteoporosis, dan tidak terdapat riwayat penyakit kronik (diabetes melitus, asma bronkiale) sebelumnya. Pada saat operasi tersebut diambil tulang sebagai sampel untuk dilakukan pemeriksaan arsitektur tulang dengan scanning electron microscope (SEM) dan komposisi atom mineral tulang dengan $X$-ray fluorescence (XRF).

Kelompok penelitian dibagi dua kelompok berdasarkan atas gambaran SEM yaitu kelompok porosis (sudah ditemukan lubang trabekular) dan kelompok nonporosis (belum ditemukan lubang trabekular).

Uji t dilakukan untuk dapat menentukan perbedaan kadar atom mineral pada kelompok nonporosis bila dibandingkan dengan kelompok porosis. Pemeriksaan bone mineral density (BMD) dilakukan dengan dual $x$-ray absorptiometry di RSUD Ulin Banjarmasin, Kalimantan Selatan. Analisis scanning electron microscope (SEM) dan XRF dilaksanakan di Laboratorium Fisika Universitas Negeri Malang. Penelitian dilakukan periode bulan Agustus 2010 sampai Januari 2011. Penelitian ini telah mendapat persetujuan etik dari Komite Etik Penelitian Fakultas Kedokteran Universitas Brawijaya Malang (No 0259/EC/ KEPK-JK/08/2010). 


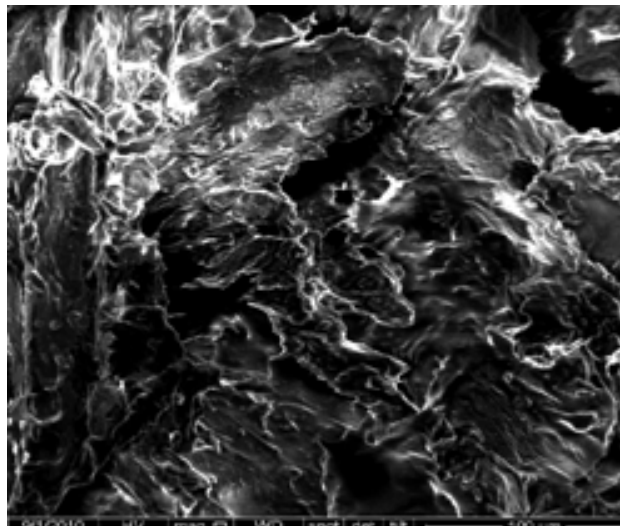

A

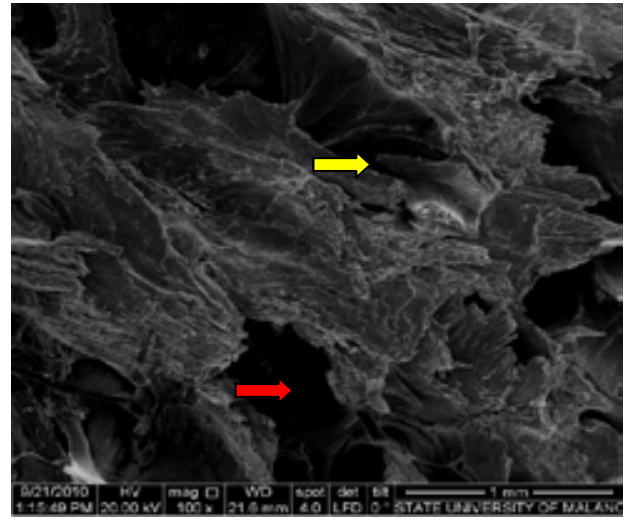

B

Gambar 1 Gambaran Tulang Trabekular pada SEM Nonporosis (A) dan SEM Porosis (B) dengan Perbesaran 100 Kali. Keterangan: lubang trabekular (panah merah), puntung trabekular (panah kuning)

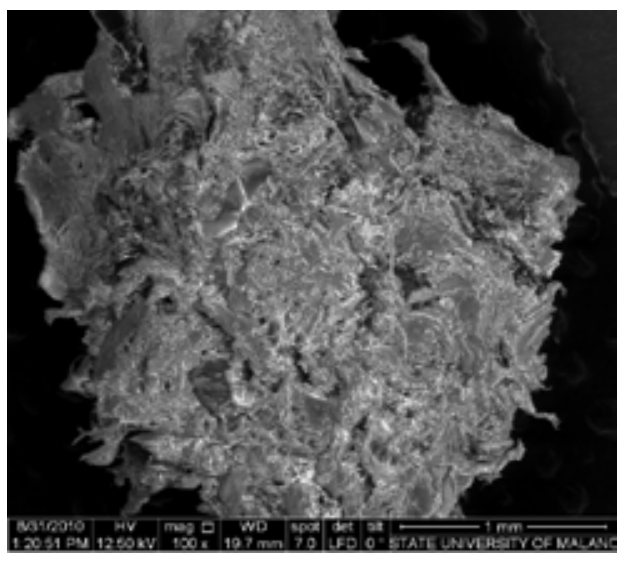

A

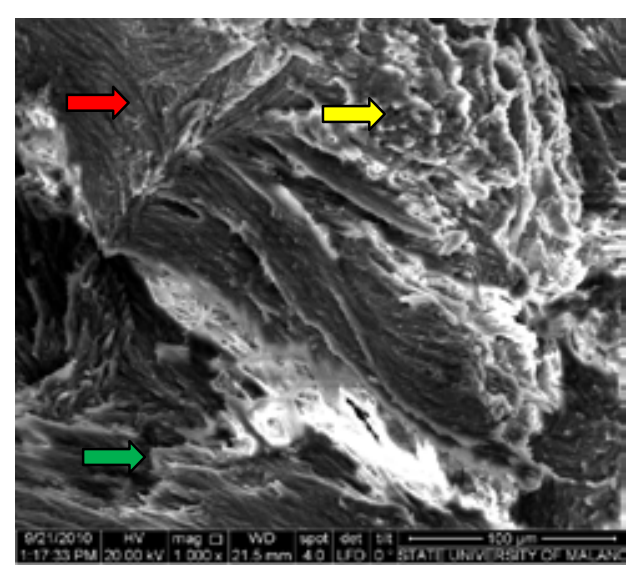

B

Gambar 2 Gambaran Tulang Trabekuler pada SEM Nonporosis (A) dan SEM Porosis (B) dengan Perbesaran 1.000 Kali. Keterangan: serat fibril utuh (panah merah), serat fibril putus (panah hijau), dan struktur granul (panah kuning)

\section{Hasil}

Penelitian ini melibatkan 10 penderita dengan gambaran SEM porosis dan 7 penderita dengan gambaran SEM nonporosis. Berdasarkan hasil analisis SEM didapatkan perbedaan gambaran arsitektur tulang antara pasien dengan gambaran SEM porosis dan nonporosis. Gambaran SEM nonporosis memperlihatkan struktur trabekular yang mendatar dan belum ditemukan lubang, sedangkan pada porosis mulai terdapat lubang dan penipisan trabekular serta muncul puntung yang menurunkan integritas trabekular (Gambar 1).

Pada analisis XRF didapatkan komposisi atom yang lebih tinggi pada tulang SEM nonporosis

Tabel Kadar Atom (\%) Rata-rata pada Kedua Kelompok

\begin{tabular}{lcccccccccc}
\hline \multicolumn{1}{c}{ Subjek } & $\mathbf{P}$ & $\mathbf{S}$ & $\mathbf{F e}$ & $\mathbf{N i}$ & $\mathbf{C u}$ & $\mathbf{Z n}$ & $\mathbf{C r}$ & $\mathbf{M o}$ & $\mathbf{S i}$ & $\mathbf{C a}$ \\
\hline Porosis & 19,27 & 1,87 & 3,19 & 1,45 & 2,15 & 0,29 & 0,40 & 0,34 & 0,20 & 58,67 \\
Nonporosis & 19,48 & 5,81 & 5,49 & 1,75 & 1,81 & 0,02 & 19,56 & 0,25 & 0,32 & 50,30 \\
Nilai p & 0,96 & 0,24 & 0,10 & 0,67 & 0,71 & 0,19 & 0,28 & 0,88 & 0,74 & 0,43 \\
\hline
\end{tabular}


yaitu P, S, Fe, Ni, Cr, dan Si. Sebaliknya, komposisi atom yang lebih tinggi pada tulang SEM porosis meliputi $\mathrm{Cu}, \mathrm{Zn}, \mathrm{Ca}$, dan Mo. Dengan analisis uji $\mathrm{t}$ tidak berpasangan tidak didapatkan perbedaan persentase atom kelompok porosis dibandingkan dengan kelompok nonporosis $(\mathrm{p}>0,05)$ (Tabel).

\section{Pembahasan}

Tulang trabekular memiliki sifat sensitif terhadap hormon atau faktor biologis yang terlibat dalam metabolisme. Logam berat agar dipertimbangkan sebagai salah satu faktor yang penting untuk menentukan arah dan intensitas proses metabolik tulang dan juga berbahaya bagi organisme ketika terjadi pergantian beberapa elemen penting dalam struktur tulang. Hal ini akan memicu perubahan proses biokimia dan kekuatan tulang mengalami degeneratif. ${ }^{13}$

Dalam pandangan nanomaterial, perbedaan mikrostruktur tulang diduga didasari oleh sifat atom mineral dalam pembentukan komposit. ${ }^{16}$ Atom mineral tertentu di tulang akan memberikan konsekuensi aktivitas substitusi atau inkorporasi dengan atom mineral lain, selanjutnya mekanisme ini akan menentukan suatu mikrostruktur tulang, terlibat dalam ketidakseimbangan antara formasi dan resorpsi tulang, serta perubahan ikatan dan struktur organik tulang. ${ }^{17}$

Berdasarkan atas hasil x-ray absorptiometry didapatkan komposisi atom yang lebih tinggi pada tulang SEM nonporosis yaitu $\mathrm{P}, \mathrm{S}, \mathrm{Fe}, \mathrm{Ni}$, $\mathrm{Cr}$, dan Si. Sebaliknya, komposisi atom yang lebih tinggi pada tulang SEM porosis meliputi $\mathrm{Cu}, \mathrm{Zn}, \mathrm{Ca}$, dan Mo. Dengan analisis uji t tidak didapatkan perbedaan yang bermakna persentase atom antara kelompok porosis dan nonporosis. Hasil yang tidak bermakna ini mengindikasikan terdapat perbedaan penataan atom mineral dalam struktur kristal hidroksiapatit yang didasarkan pada aktivitas substitusi atau inkorporasi atom suatu tulang. Aktivitas substitusi atau inkorporasi atom menyebabkan penggantian atom mineral yang mengalami defisiensi atau berlebih dengan atom mineral lain yang mempunyai valensi sama pada struktur kristal hidroksiapatitnya. Penataan atom mineral di dalam struktur hidroksiapatit ini akan menentukan ukuran serta bentuk struktur hidroksiapatit dan akhirnya ukuran dan bentuk struktur hidroksiapatit akan menentukan porositas dan arsitektur tulang, misalnya struktur fibril dan terdapat granul.

Simpulan, perkembangan arsitektur dari poros tulang trabekular osteoporosis tidak didasari oleh kuantitas atom mineral tulang.

\section{Daftar Pustaka}

1. Brandao CM, Lima MG, Silva AL, Silva GD, Guerra AA Jr, Acurcio Fde A. Treatment of postmenopausal osteoporosis in women: a systematic review. Cad Saude Publica. 2008; 24(suppl 4):592-606.

2. Duncan EL, Brown MA. Genetic studies in osteoporosis-the end of the beginning. Arthritis Res Ther. 2008;10(5):214.

3. Lerner UH. Bone remodeling in postmenopausal osteoporosis. J Dent Res. 2006;85(7):584.

4. Huang Q, Kung AWC. Genetic of osteoporosis. Mol Genet Metab. 2006; 88:295-306.

5. Handa R, Ali Kalla A, Maalouf G. Osteoporosis in developing countries. Best Pract Res Clin Rheumatol. 2008;22(4):693708 .

6. Zhang ZL, Qin YJ, Huang QR, Hu YQ, Li $\mathrm{M}$, He JW, dkk. Bone mineral density of the spine and femur in healthy Chinese men. Asian J Androl. 2006;8(4):419 $\square-27$.

7. Lynn HS, Lau EM, Au B, Leung PC. Bone mineral density reference norms for Hong Kong Chinese. Osteoporosis Int. 2005;16(12):1663-8.

8. Sadat-Ali M, Al-Elq A. Osteoporosis among male Saudi Arabs: a pilot study. Ann Saudi Med. 2006;26(6):450-4.

9. El-Desouki MI, Sulimani RA. High prevalence of osteoporosis in Saudi men. Saudi Med J. 2007(5);28:774-7.

10. PEROSI. Indonesian Osteoporosis: fact, figures, and hopes. Jakarta: Indonesian Osteoporosis Association; 2009.

11. Dhanwal DK, Dennison EM, Harvey NC, Cooper C. Epidemiology of hip fracture: Worlwide geographic variation. Indian J Orthop. 2011;45(1):15-22.

12. Cummings SR, Melton LJ III. Epidemiology and outcomes of osteoporo fractures. Lancet. 2002;359(9319):1761-7.

13. Brodziak-Dopierala B, Kwapulinski J, Gajda $Z$, Toborek J, Bogunai M. Changes of heavy metal concentrations in cross-sections of human femur head. Biol Trace Elem Res. 2006;114(1-3):107-16.

14. Zaichick V, Tzaphlidou M. Calcium and phosphorus concentrations and the calcium/ phosphorus ratio in trabecular bone from the femoral neck of healthy humans as determined by neutron activation analysis. Appli Radiat Isot. 2003;58(6):623-7.

15. Osada M, Izuno T, Kobayashi M, Sugita M. Relationship between environmental exposure to cadmium and bone metabolism 
in a non-polluted area of Japan. Environ Health Prev Med. 2011;16(6):341-9.

16. Vallet-Regi M, Arcos D. Biomimetic nanoceramics in clinical use: from materials to applications. Cambridge: The Royal Society of Chemistry, Thomas Graham House, Science Park; 2008.
17. Noor Z, Sumitro SB, Hidayat M, Rahim AH, Sabarudin A, Umemura T. Atomic mineral characteristics of Indonesian osteoporosis by high-resolution inductively coupled plasma mass spectrometry. Sci World J. 2012;372972. 